\title{
Conventional High Pressure versus Newly Developed Continuous-Flow Ureterorenoscope: Urodynamic Pressure Evaluation of the Renal Pelvis and Flow Capacity
}

\author{
MAURICE STEPHAN MICHEL, M.D., Ph.D.,* PATRICK HONECK, M.D.,* and PETER ALKEN, M.D.
}

\begin{abstract}
Purpose: We evaluated the pressure and flow relation of a newly developed continuous-flow ureterorenoscope (URS) in comparison with a common ureterorenoscope in an ex-vivo urinary tract model.

Materials and methods: Ureterorenoscopies were performed with the newly developed $10.5 \mathrm{~F}$ continuousflow URS with separate inflow and outflow channel and a conventional 10.5F URS with a combined inflow and outflow channel. The ex-vivo model consisted of complete urinary tracts of domestic pigs obtained freshly from the slaughterhouse. Both instruments were used in five urinary tracts, and six ureterorenoscopies were performed in each urinary tract. The pressure in the renal pelvis (RP) was measured during each procedure. Height of the irrigation solution above renal level and flow capacity were also documented.

Results: The conventional URS showed a correlation of intrapelvic pressure and the height of the irrigation solution above renal level rising from $20 \pm 3.7 \mathrm{~cm} \mathrm{H}_{2} \mathrm{O}$ at a solution level of $20 \mathrm{~cm}$ to a plateau pressure of $40 \pm 3.3 \mathrm{~cm} \mathrm{H} \mathrm{H}_{2} \mathrm{O}$ with a distinct renal influx at a level of $50 \mathrm{~cm}$. The maximum flow capacity at a solution level of $20 \mathrm{~cm}$ was $0.2 \mathrm{~mL} / \mathrm{min}$ rising to a flow capacity of $0.5 \mathrm{~mL} / \mathrm{min}$ at $40 \mathrm{~cm}$ above renal level. The maximum flow capacity for the continuous-flow URS was about 100 times higher, rising from $20 \mathrm{~mL} / \mathrm{min}$ at a solution level of $20 \mathrm{~cm}$ to $70 \mathrm{~mL} / \mathrm{min}$ at $40 \mathrm{~cm}$ above renal level. The intrapelvic pressure was $15 \pm 2.1 \mathrm{~cm} \mathrm{H}_{2} \mathrm{O}$ at a solution level of $20 \mathrm{~cm}$ and did not exceed the physiologic renal pressure of $20 \mathrm{~cm} \mathrm{H}_{2} \mathrm{O}$ even if the irrigation solution was at a height of $100 \mathrm{~cm}$ above renal level.

Conclusion: The newly developed continuous-flow URS provides a 100 times higher flow capacity while simultaneously preserving the physiologic pressure in the RP compared with the conventional URS. These characteristics will improve visibility and reduce retrograde stone manipulation, operative time, and complications under clinical conditions.
\end{abstract}

\section{INTRODUCTION}

A DVANCES IN TECHNOLOGY have generated ureterorenoscopes (URSs) with increasingly smaller diameters. The price for reduction in diameter in most URSs is one common channel for irrigation and the passage of instruments, resulting in decreased irrigation. Good irrigation is vital for dilation of the ureter and collecting system, for enhancing instrument passage, and for vision.

When using common URSs with combined inflow and outflow channel, problems concerning good sight on the one hand and high pressure in the ureter or renal pelvis (RP) in combination with retrograde stone manipulation on the other hand can occur.

Various techniques have been tried to improve irrigation, including gravity drainage, pressurized irrigant bags, and handheld or foot-activated syringe-based systems. ${ }^{1}$ All these solu- tions will lead to an increased intrapelvic pressure as well as an increased risk of retrograde stone manipulation.

The newly developed continuous flow URS (Fig. 1) (Karl Storz, Tuttlingen, Germany) has a separate inflow and outflow channel that enables the user to maintain continuous irrigation. The aim of this study was the evaluation of pressure and flow relation using a common URS in comparison with a newly developed continuous-flow URS using an ex-vivo urinary tract model.

\section{MATERIALS AND METHODS}

Ureterorenoscopies were performed with the newly developed continuous-flow URS with separate inflow and outflow channel (Fig. 1) and a conventional URS with a combined inflow and outflow channel (Fig. 2) (Karl Storz, Tuttlingen, Ger-

Department of Urology, Mannheim University Hospital, Mannheim, Germany.

*These authors contributed equally to this research. 


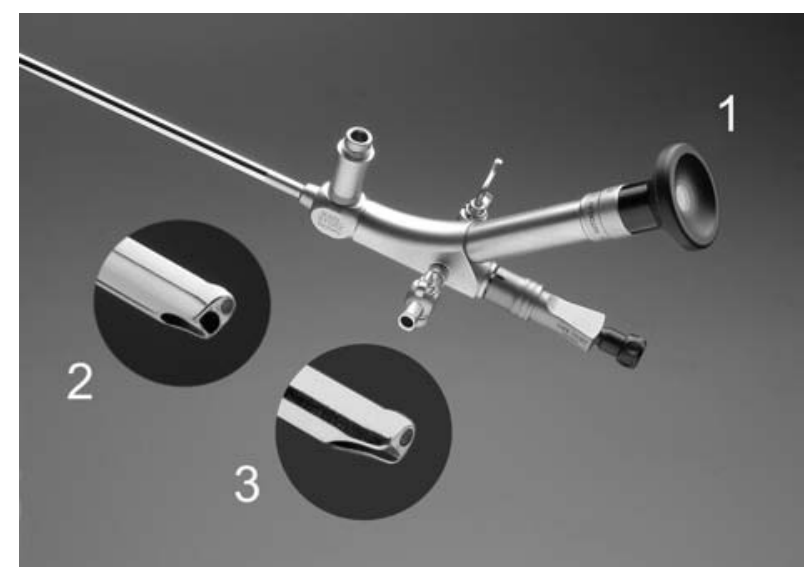

FIG. 1. Continuous-flow ureterorenoscope (URS). $1=$ continuous-flow URS; 2 = tip of the continuous-flow URS showing the separate inflow and outflow channel; $3=$ tip of a conventional URS showing the combined inflow and outflow channel.

many). Both URSs had a total sheath diameter of $10.5 \mathrm{~F}$. The continuous-flow URS has a $5 \mathrm{~F}$ working channel and a $3.8 \mathrm{~F}$ irrigation channel, whereas the conventional URS has only one 5.5F working channel The ex-vivo model consisted of complete urinary tracts of domestic pigs obtained freshly from the slaughterhouse. Both instruments were used in five urinary tracts, and six ureterorenoscopies were performed in each urinary tract.

To measure the pressure in the RP, a $6 \mathrm{~F}$ cystometry catheter (Porgès S. A., France) was introduced into the RP, fixed with a suture, and sealed watertight with cryanoacrylate glue. Pressure measurement was performed using a urodynamic measuring system (Dantec Duet Multi). The urinary tract was held in place by micromanipulators. Height of the irrigation solution above renal level and flow capacity in $\mathrm{mL} / \mathrm{min}$ was also documented.

\section{RESULTS}

\section{Conventional URS}

The intrapelvic pressure correlated with the height of the irrigation solution above renal level. The maximum flow capacity at a solution level of $20 \mathrm{~cm}$ was $0.2 \mathrm{~mL} / \mathrm{min}$, rising to a flow

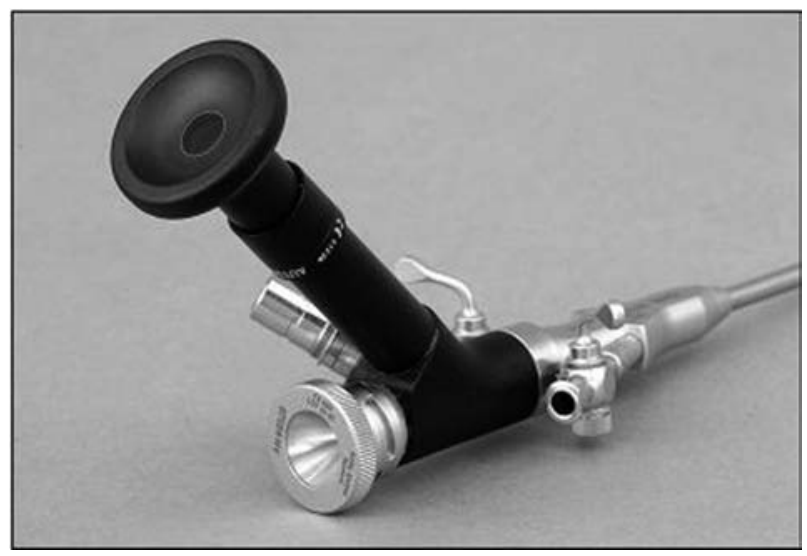

FIG. 2. Conventional ureterorenoscope. capacity of $0.5 \mathrm{~mL} / \mathrm{min}$ at a solution level of $40 \mathrm{~cm}$ above renal level (Fig. 3). The intrapelvic pressure also correlated with the height of the irrigation solution, rising from $20 \pm 3.7 \mathrm{~cm}$ $\mathrm{H}_{2} \mathrm{O}$ at a solution level of $20 \mathrm{~cm}$ to $39 \pm 2.5 \mathrm{~cm} \mathrm{H}_{2} \mathrm{O}$ at a level of $40 \mathrm{~cm}$. At a level of $50 \mathrm{~cm}$, a plateau pressure of $40 \pm 3.3$ $\mathrm{cm} \mathrm{H}_{2} \mathrm{O}$ was reached, and a distinct pyelolymphatic and pyelovenous backflow was observed (Fig. 4).

\section{Continuous-flow URS}

The maximum flow capacity for the continuous-flow URS was about 100 times higher than the conventional URS. At a solution level of $20 \mathrm{~cm}$, the maximum flow capacity was 20 $\mathrm{mL} / \mathrm{min}$, rising to a flow capacity of $70 \mathrm{~mL} / \mathrm{min}$ at a solution level of $40 \mathrm{~cm}$ above renal level (Fig. 3).

The intrapelvic pressure was $15 \pm 2.1 \mathrm{~cm} \mathrm{H}_{2} \mathrm{O}$ at a solution level of $20 \mathrm{~cm}$ and $15 \pm 1.5 \mathrm{~cm} \mathrm{H}_{2} \mathrm{O}$ at a level of $40 \mathrm{~cm}$ (Fig. 4). In contrast to the conventional URS, the intrapelvic pressure did not exceed the physiologic renal pressure of $20 \mathrm{~cm} \mathrm{H}_{2} \mathrm{O}$. Even if the irrigation solution was at a height of $100 \mathrm{~cm}$ above renal level, the intrapelvic pressure was $17.5 \pm 1.3 \mathrm{~cm} \mathrm{H}_{2} \mathrm{O}$.

\section{DISCUSSION}

Because visibility during ureterorenoscopy depends on a number of factors, such as bleeding, floating debris, and illumination as well as irrigation, there is no definite minimum flow rate for good visibility. Clinical experience indicates that the flow rates provided by gravity irrigation generally are adequate for viewing purposes. ${ }^{2}$ If active bleeding occurs while a working instrument is in use, however, visibility becomes obscured. Manual irrigation may be used in such cases, but, unlike gravity irrigation, manual irrigation is associated with a

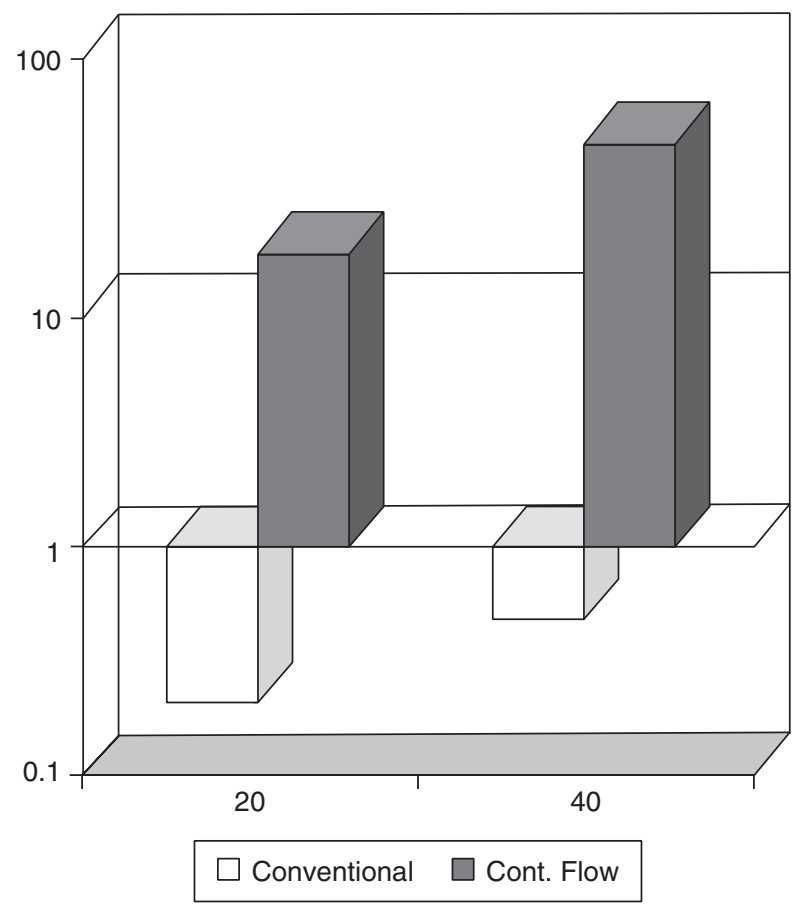

FIG. 3. Flow capacity relative to height of flow solution 


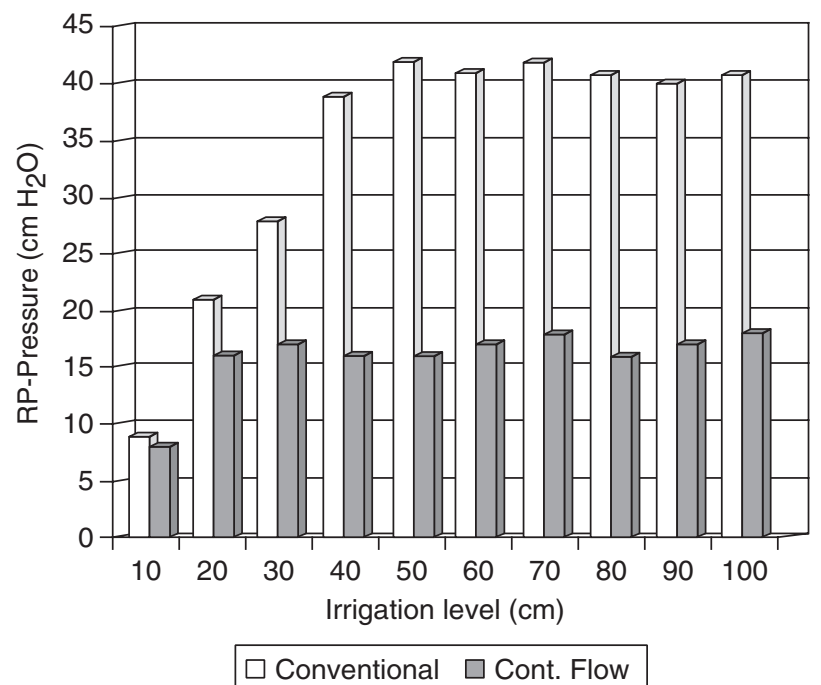

FIG. 4. Renal pelvic pressure relative to height of flow solution.

highly variable rise in intrapelvic pressure that might reach levels potentially damaging to the kidney. ${ }^{3}$

Fluid absorption secondary to excessive irrigation pressures can be detrimental, as evidenced by the development of sepsis during percutaneous nephrolithotomy of infection stones. ${ }^{4,5}$ Similarly, pyelolymphatic and pyelovenous backflow can occur during retrograde ureteral manipulation and occasionally during aggressive retrograde pyelography.

The effects of elevated renal pelvic pressures have been documented in animal studies. ${ }^{5}$ High-pressure irrigation of more than $20 \mathrm{~cm} \mathrm{H}_{2} \mathrm{O}(150 \mathrm{~mm} \mathrm{Hg})$ produces significant pathologic changes in minipig kidneys. Vigorous hand irrigation also generates a maximum pressure of $60 \mathrm{~cm} \mathrm{H}_{2} \mathrm{O}(440 \mathrm{~mm} \mathrm{Hg})$ with the rigid URS in human subjects during ureteroscopic manipulation. ${ }^{3}$

In the research by Dogan and coworkers, ${ }^{6}$ absorption of perfusion fluid during percutaneous nephrolithotomy was a high risk factor for postoperative fever.

In our study, the conventional URS reaches pressure levels that cause consecutive renal influx at a intrapelvic pressure of $40 \mathrm{~cm}$ $\mathrm{H}_{2} \mathrm{O}$ only by using gravity irrigation. Manual irrigation would certainly increase the intrapelvic pressure as well as renal influx and subsequent postoperative complications. The continuous-flow URS offers a constant flow rate without reaching high intrarenal pressure levels. Even at an irrigation solution height of $100 \mathrm{~cm}$ above renal level, no renal influx could be observed, and the physiologic intrarenal pressure of $20 \mathrm{~cm} \mathrm{H}_{2} \mathrm{O}$ was not exceeded.

Regarding the irrigation flow capacity, the continuous-flow URS has a 100 times higher flow capacity than the conventional URS by simultaneously maintaining a low intrarenal pressure. This is below the threshold of $30 \mathrm{~cm} \mathrm{H}_{2} \mathrm{O}$ commonly quoted as a target maximum and less than the pressure at which pig kidneys show acute and chronic damage in the form of renal scarring. ${ }^{5,7}$ There have been no documented human cases of renal detriment secondary to elevated intrarenal pressures, probably as a result of failure to assess for minor or insignificant damage that is not routinely measurable with standard tests of renal function and no indications for renal biopsy after routine ureteroscopic procedures.

If transferred into clinical use, it can be assumed that the higher flow capacity and the constant flow rate combined with a low intrarenal pressure will consecutively lead to better visibility and simultaneously a lower risk for retrograde stone manipulation because of the decreased pressure situation. The fact that the intrarenal pressure is constantly kept below $30 \mathrm{~cm} \mathrm{H}_{2} \mathrm{O}$ will also lead to a reduced risk of complications.

\section{CONCLUSION}

The newly developed continuous-flow URS provides a 100 times higher flow capacity compared with the conventional URS. Simultaneously, the preservation of a physiologic pressure in the renal pelvis is preserved even at high irrigation pressure levels. It can be assumed that these characteristics will improve visibility and reduce retrograde stone manipulation, operative time, and complications under clinical conditions. The results of this ex-vivo study have to be confirmed under in-vivo conditions.

\section{AUTHOR DISCLOSURE STATEMENT}

The authors declare that Prof. Michel is a co-inventor of the continuous flow URS. They received no financial or other support from Karl Storz for conducting and processing this study.

\section{REFERENCES}

1. Blew BD, Dagnone AJ, Pace KT, Honey RJ. Comparison of Peditrol irrigation device and common methods of irrigation. J Endourol 2005;19:562-565.

2. Bagley DH. Flexible ureteroscopy. Semin Urol 1989;7:7-15.

3. Wilson WT, Preminger GM. Intrarenal pressures generated during flexible deflectable ureterorenoscopy. J Endourol 1990;4:135.

4. Cadeddu JA, Chen R, Bishoff J, Micali S, Kumar A, Moore RG, Kavoussi LR. Clinical significance of fever after percutaneous nephrolithotomy. Urology 1998;52:48-50.

5. Schwalb DM, Eshghi M, Davidian M, Franco I. Morphological and physiological changes in the urinary tract associated with ureteral dilation and ureteropyeloscopy: An experimental study. J Urol 1993;149:1576-1585.

6. Dogan HS, Sahin A, Cetinkaya Y, Akdogan B, Ozden E, Kendi S. Antibiotic prophylaxis in percutaneous nephrolithotomy: Prospective study in 81 patients. J Endourol. 2002;16:649-653.

7. Hinman F, Redewill FH. Pyelovenous back flow. JAMA 1926;87:1287.

Address reprint requests to: Maurice Stephan Michel, M.D., Ph.D.

Department of Urology Mannheim University Hospital

Theodor-Kutzer-Ufer 1-3 68161 Mannheim, Germany

E-mail: maurice-stephan.michel@uro.ma.uni-heidelberg.de

\section{ABBREVIATIONS USED}

$$
\begin{aligned}
\mathrm{RP} & =\text { renal pelvis } \\
\mathrm{URS} & =\text { ureterorenoscope }
\end{aligned}
$$


